\title{
The Application Based on Multimedia Technology in Teaching
}

\author{
Gang Wang ${ }^{1}$, Jingfeng Liu ${ }^{2}$, Hui Chen ${ }^{2}$, Xiaotong Tong ${ }^{2}$, Shaobo $\mathrm{He}^{2}$, Jianchun $\mathrm{Xu}^{3}$, Baomin \\ Wang $^{2}$, Guocai $\mathrm{Xu}^{2}$, Ying Wang ${ }^{2}$ \\ ${ }^{1}$ Information and Communication Branch, State Grid Liaoning Electric Power Co., Ltd. \\ ${ }^{2}$ Fushun power supply company, State Grid Liaoning Electric Power Co., Ltd. \\ ${ }^{3}$ Dandong power supply company, State Grid Liaoning Electric Power Co., Ltd.
}

Keywords: multimedia teaching; traditional teaching; courseware; teaching effect

\begin{abstract}
Multimedia teaching is accepted by many students and teachers for its' own advantages like lifelikeness, visualization and large information content. Some advices of dealing with the relationship between multimedia teaching and traditional instruction were proposed in this paper, and some advantages and disadvantages of multimedia teaching were also given here. According to author's many years of media teaching experience, some kinds of specific recommendations were also brought up here like the manufacture of media courseware, how to express the leading role of teacher, promotion of the interaction between teachers and students and how to transfer students' enthusiasm.
\end{abstract}

\section{Introduction}

Multimedia teaching is a method that supports teachers to complete teaching, and it contains graphics, images, text, animation, video and sound which are all transferred by computer calculating. We often call this method as Computer Aided Instruction (CAI). Media teaching has become more and more important to most of the colleges and universities. It's a new teaching mode of modern school education. It is the inevitable outcome of the combination of multimedia technology and educational theory. Using the multimedia technology, teachers are hoping to enrich students' enthusiasm for learning and improve teaching efficiency and effectiveness.

\section{The difference of multimedia and traditional teaching}

Teaching methods not only can be traditional chalk, blackboard, flip charts, wall charts and other common teaching aids, but also it can be modern multimedia. Multimedia teaching and traditional teaching methods of teaching are complementary teaching methods. As a new teaching method, teaching has its irreplaceable multimedia features and functions. Compared with the traditional teaching methods, the advantages and disadvantages of multimedia teaching can be summarized as follows.

\subsection{The advantages of multimedia teaching}

(1) Stimulating students' enthusiasm for learning

It's easy for multimedia teaching method to product realistic multimedia effects, and it can make teaching more substantial, more vivid and more attractive. It will help to stimulate students' interest and enthusiasm for learning. Stimulate enthusiasm for learning to students is more important than teaching them direct knowledge , because knowledge is in constant development and renewal, classroom teaching can't be good enough for a lifetime of knowledge to the students, and active quest, the quality of the pioneering will benefit for students' life.

(2) Helping students understand difficult knowledge

By strong sensory stimulation, multimedia teaching can left students a deep impact on the teaching content. It can break the boundaries of time and space to make abstract concepts concrete, complex process simple, boring content visualize. It will help students understand what they have 
learned. Limited by ordinary limits, the traditional teaching aids can't teach a thorough theoretical abstraction and complexity of the language to students. So it restricts students' knowledge and understanding of the difficult.

(3) Large amount of information to enrich the teaching content

Multimedia can enrich the teaching content, expand and deepen the depth and breadth of student learning. The traditional teaching model requires teachers to continue writing on the blackboard, blackboard clean and organizing language, so it slow pace of curriculum, limits the amount of information.

\subsection{Defects in multimedia teaching}

(1) Reduce the effect of students' classroom lectures

Multimedia teaching contain Large amount of information, and its' information change fast. The rapidly changing information impact on students in a short time, and the stimulus intensity is not enough. Also the eyes and minds of the students stay a short time on the courseware, and they have no time to understand, and no time to digest and absorb, thus reducing the effect of students' classroom lectures. During the traditional teaching, teachers can teach as well as write on the blackboard, which can enhance students' memory, and help students understand the content of teaching, so that to strengthen the knowledge. What's more it can be more complete and scientifically demonstrate knowledge of the occurrence, formation, so that knowledge is coherence, and also leave thinking space for students. Substantial and rapid information make students can't write a good class notes, thus affect the learning, review and consolidation of the knowledge. Students can't transfer short-term memory into long-term memory through the review, so students can't grasp book knowledge.

(2) Lack of teachers and students of the question of emotional communication

Teachers often too much rely on the multi-media, and reduce to the explain weight in the multimedia teaching process. Teachers focus too much on the keyboard, mouse, and screen, who become a computer operator and guider, and with little attention to the subject - students.

(3) Ignore the leading role of teachers

Due to dark lighting, large screen and teachers in the same position, and screen colours, vivid animation, changing sound effects are more attractive to students, so the teacher's leading role is ignored.

(4) Too strong sensory stimulation is easy for students to advance fatigue

Intense sound, light, electrical signals and a lot of knowledge and information can easily cause students' visual, auditory and brain become fatigue, which will affect students to understand the follow-up knowledge.

In summary, although it's an effective, advanced teaching mode, but it is still not as good as the traditional teaching. That is conducive to teaching students to learn the traditional moral and character education, and it will help teachers to guide, direct teaching, and control students and so on. Multimedia teaching is the inheritance, development, reform and innovation of traditional teaching. We should not make multi-media teaching and traditional teaching against each other, but strengthen the combination of them.

\section{How to make multimedia courseware}

\subsection{The selection of courseware content}

The same fundamental purpose of multimedia technology in teaching is to fully and efficiently complete the task of teaching. So the topics of appropriate courseware is to meet the current curriculum requirements and appropriate curriculum, and teaching content should be specific, while the materials should oriented by students' teaching material which in order to facilitate students' prep and review. On this basis, teachers can collect, download the courses or subjects related to the latest data and information, and then to edit, organize them to reflect the courseware, expand the students' knowledge. 


\subsection{The request to the word and picture}

A good courseware not only express the full teaching content, teaching materials should be re-create, so that students have profound impressed of the teaching content. This requires when the teacher make the courseware, the teacher have a in depth and thorough to the content, clearly important and difficult on each chapter, well-designed every screen to make the reasonable of graphical text layout, concise and clear, clear picture quality, eye-catching, color suitable , important and difficult is prominent. Should not simply enter the content of textbooks on the screen .In this way, the writing on the blackboard content is increased, it did not really play to the advantages of multi-media teaching. Although eliminating the time of classroom writing on the blackboard, the presentation is poor and a focus not prominent, teaching methods are no substantive change. The result is teaching effect worse than the traditional way of blackboard and chalk.

\subsection{The request to the courseware background}

Courseware should be kept the same style, with the some background, and background colors should be soft, coordinated with teaching content reasonable, reduce the slack of students' attention, focus on students' attention on teaching content. Otherwise, one-sided pursuit of the beauty of the background or a beautiful picture, even add some unnecessary music, animation, the results is students most profound impression is beautiful images on the courseware in whole class, it is weakened corresponding to knowledge of learn.

\subsection{The courseware update}

Due to make their multimedia courseware by themselves, through application, it will clearly express what is reasonable, what is not appropriate for mobilized of the enthusiasm and creativity of the students. At the same time, we still need more communication with students during recess, let students talk about the views of courseware from their own point of view easy to learn. After school, according to gathered the information of feedback, amended the problem of courseware in time and improve the quality of courseware production from the substantial improvement of the teaching content, teaching schedule, the display font size and color, the picture of freshness, with the latest knowledge of course content and other aspects.

\section{The considerations of multimedia teaching}

\subsection{Teachers should fully play the leading role}

Teachers should identify their leading role in teaching, focusing on the following points:

(1) The multimedia course must meet the physical and mental characteristics and real life of students, from the point of view of fully mobilize the attention and ability of understand of students, designed of time and order of various media in teaching process;

(2) In order to avoid ahead of a recession of the attention of students, teachers should ensure that the multimedia classroom teaching amount of information is appropriate on each section;

(3) Note the use of teachers' body language. Body language includes temperament, gestures, voice and facial expression, vivid emotion. Beautiful body language allows students to better communication with teachers on emotion. Only use of various teaching methods correctly and teacher's body language, it can improve the teaching effect well.

\subsection{Interaction and communication with students}

Teaching activities in classroom is most important and most frequently part of interaction about teachers and students. The classroom behavior of teacher plays a subtle role to students. Teachers should be good at empathy. And become a good partner in student learning. In the multimedia teaching, teachers should pay close attention to facial expressions of students at class and firmly grasp the attention of students in time by teachers ask questions, call in questions and tell stories (and lectures related), or ask questions to students, debate, etc. Teachers should guide students to think and answer questions, and lectures be adjusted accordingly at any time. 


\subsection{Combined with the traditional blackboard}

Although use of multimedia technology save a lot of time of teachers to writing on the blackboard in the teaching classroom, in order to get better teaching effect than simply writing on the blackboard, teachers should spend more time for do a lesson panning before the full lesson. Not only spend a lot time for make multimedia courseware well, but also prepared carefully from the content, time, form and so on. According to different teaching content choice of different forms of teaching, to illustrate the problem form more maps, tables, or animations, through the multimedia courseware to support teaching and enhance intuitive, vivid of classroom teaching. Do that, student facilitate understanding. If some of content is the conceptual and reasoning, teachers must be brilliant, vivid explanations, and base on reflect of student's in classroom, to provide examples of appropriate and writing on the blackboard to be interpreted for achieve good results. Otherwise, only keep the multimedia courseware "Play" according with order, the teacher simply read the content on the slide, without any writing on the blackboard and explain, this class is a "slide show lesson". Teachers completely ignoring the experience and acceptance, understanding of students in the classroom, it is difficult to achieve the desired effect.

\subsection{The showing mode and speed}

After implementation of multi-media teaching, some students think that there are some teachers teach content too much and progress too fast each lesson, causing students to dazzle, have no time to be granted a thorough understanding of the content, analysis, integration and then stored, resulting in greatly reduced learning the effect. The mainly reason of these problems is when the use of multimedia teaching, the teacher did not explain the courseware combine with the teacher's presentation. During the design of courseware presentation and show, the showing speed of each slide and the speed of the interface between the various components should manner with the teacher's explanation. Asking questions, inspiration and comment should be combined rationally, and teacher should leave the time for students to think. It can facilitate the teaching effectiveness, and students can communicate with teachers about the effect of teaching.

\section{Conclusion}

Multimedia teaching is a means of aid-teaching like traditional teaching, both advantages and disadvantages. The teacher play a leading role not only work hard in make multimedia courseware but also should flexible use of traditional teaching methods in the multimedia teaching. Through the process lively of teaching, enhance enthusiasm of student learning, increase learning efficiency.

\section{References}

[1] Wenhua Chen. Multimedia Technology[M]. BeiJing: China Machine Press, 2006.

[2] Juan Wang. Analysis of Multimedia Technology and Multimedia Teaching[J]. Journal of College of Engineering and Technology, 2004, 16(3):47-511

[3] Fang Yang. Taking about Integration about Multimedia teaching and traditional teaching [J], Education and Vocational, 2002, 6:25-26

[4] Hui Wang. The Controversial Issues of Multimedia Teaching[J]. Journal of Hebei Radio and Television University, 2004, 9(3):52-53

[5] Chengzhong Li, Xunsun Wang. The Control Theory of Education[M]. Changchun: Northeast Normal University Press, 1986. 